\title{
Capitalising new knowledge through R\&D alliances: Evidence from Catalan technology centres
}

\author{
Jasmina Berbegal-Mirabent
}

Department of Economy and Business Organisation. Univeristat Internacional de Catalunya. C. Immaculada, 22. 08017 Barcelona, Spain. Email: jberbegal@uic.es *Corresponding author

\section{Rocio de la Torre}

Institute for Advanced Research in Business and Economics (INARBE). Business Administration Department. Public University of Navarre. Campus de Arrosadia. 31006 Pamplona. Email: rocio.delatorre@unavarra.es

\section{Dolors Gil-Doménech}

Department of Economy and Business Organisation. Univeristat Internacional de Catalunya. C. Immaculada, 22. 08017 Barcelona. Email: mdgil@uic.es

\begin{abstract}
Science-industry R\&D alliances have been a longstanding object of analysis in the literature as they are reinforced by the changing global economy and the fast-moving nature of technological research. In order to advance knowledge on how these alliances should be designed and managed, this paper examines whether the factors most valued by technology centres to engage in science-industry R\&D alliances have an impact on the success of the alliance: planning, partner profile, trustworthiness, IPR protection issues and communication channels. The empirical application considers 58 technology centres located in the Spanish region of Catalonia from which data were collected. First, using factor analysis, we validate that items included in the survey are indeed grouped into the five factors identified in the literature review. Second, we use qualitative comparative analysis to explore which combination of factors best explains successful R\&D alliances.
\end{abstract}

Keywords: science-industry; R\&D alliance; knowledge transfer; technology centre

Note: This is a pre-print of an article published in International Journal of Technology Management. The final authenticated version is available at:

Berbegal-Mirabent, J.; de la Torre, R.; Gil-Doménech, D. (2020). Capitalizing new knowledge through R\&D alliances: Evidence from Catalan technology centres. International Journal of Technology Management, 83(4): 246-268.

https://www.inderscienceonline.com/doi/abs/10.1504/IJTM.2020.110123 


\section{Introduction}

Knowledge and technology are central to growth and economic development. In the current era of a knowledge-based economy where organisations are called upon to foster creativity and innovation, the establishment of $\mathrm{R} \& \mathrm{D}$ alliances is intended to speed up technological innovation and reduce the time lag between discoveries and their industrial application (Wright et al., 2004). It is in this context that the formation of alliances has been proven to be one of the most common ways for incorporating, transferring and creating new knowledge (Khamseh and Jolly, 2014).

Collaborative agreements for innovation and $R \& D$ purposes can be defined as tailored relationships that, based on mutual trust and openness, generate high payoffs and act as a fundamental source for competitive advantage. Said differently, the conjoint outcome is expected to be higher than the one that could be achieved by the two parts on their own (Lambert et al., 1996). Partners in R\&D alliances receive each other's knowledge and experience, share and transfer their own knowledge and learn together to create new knowledge (Huang, 2009). This new knowledge can, in turn, be used to improve performance and productivity. Furthermore, by networking in an alliance, organisations are able to boost their capacity to glimpse new opportunities, which has been shown to have a positive effect on business development and innovation processes (Cunningham and Link, 2015; Valkokari et al., 2012).

Belderbos et al. (2004) distinguish between two types of alliances: horizontal and institutional. While the former refers to partnerships between commercial firms, the latter advocates for collaborative agreements between science-based institutions (e.g. universities and research centres) and businesses. This study focuses on this second type. Science-based institutions are often considered to be the "engines of growth" since they offer a broad spectrum of expertise, assist in the identification of technology opportunities, stages of product development and other consultancy services, and are equipped with advanced infrastructures (Spithoven and Teirlinck, 2015). Tidd and Trehwalla (1997) noticed that universities are the most widely used external source of technology. On top of that, these institutions show up as a potentially valuable source for new ideas (Kesting et al., 2018; Link et al., 2008; Ma et al., 2018).

Science-based institutions' motivations for engaging in R\&D alliances with firms usually relate to the opportunity to access fresh sources of funding for the development of new activities in areas which they are not currently investigating, principally due to the lack of resources (Lai, 2011; Muscio et al., 2014). In addition, working side by side with the industry can improve the state of the art of the transferor and generate new ideas, which can be the basis for future advanced research.

Compared to alliances between firms in which partners might be competing for the same customers (Tidström, 2009), universities and research centres are considered in a different way than commercial enterprises. Firms often undertake more 'sensitive' (for instance, the development of a new product) research at arms-length with universities than with commercial firms since they are not considered as competitors and do not operate at the same business level (their explicit mission consists of advancing new technologies with industry). Further, R\&D alliances may bring legal incentives and tax breaks to the firms $(\mathrm{Li}, 2010)$ and contribute to enhance firms' image and reputation without having the obligation to establish long-term relationships (Martínez-Noya and Narula, 2018) as collaborations can be settled within a shorter horizon. 
While the establishment of R\&D partnerships between science-based institutions and firms is desirable (Kesting et al., 2018), managing such alliances is a complex issue, requiring alternative analytical methods able to deal with this complexity. The existing literature further supports this statement. R\&D alliances are governed by a myriad of factors, the relevance and influence of which might vary from one alliance to another. This is due to the inherent heterogeneity behind each partnership (Shah and Swaminathan, 2008). Likewise, not all partners prioritise the factors in the same way (Sherwood and Covin, 2008) being necessary to examine the interplay of factors underlying participation in R\&D alliances (Lin et al., 2016). This is the starting point of several works (e.g. Berbegal-Mirabent and Llopis-Albert, 2016; Geigenmüller and Leischnig, 2017; Stejskal and Hajek, 2019) that argue that to date, the research on R\&D alliances has limited to the analysis of the "pure" effects of independent variables on an output, neglecting the existence of more realities.

Acknowledging this diversity on R\&D alliances and aiming at overcoming the limitations described above, this study proposes that there is no unique magical recipe explaining fruitful R\&D alliances but multiple paths that can be followed. Although the study of single factors is relevant and some factors might be found to be more relevant than others when examined separately (e.g. Dyer et al., 2007; Mora-Valentin et al., 2004; Plewa et al., 2013), identifying the more complex combinations of factors may lead to a better understanding of how R\&D alliances are settled (Leischnig and Geigenmüller, 2020).

Our work contributes to the existing literature in three main ways. First, we investigate different strategies (i.e. combinations of factors) research centres follow when deciding to enter in a partnership for the development of R\&D activities with an industrial partner. To do so we employ a more nuanced analytical technique, namely qualitative comparative analysis (QCA), which allows for the identification of counterintuitive and multi-dimensional causal recipes. QCA deals with the idea that various combinations of explanatory variables may result in the same outcome of interest (George and Bennett, 2005). In our case, these configurations are non-competing paths that impel the success of an R\&D alliance. Thus, instead of searching for antecedents (i.e. factors) common to all instances of the outcome, QCA embraces the causal complexity (Misangyi et al., 2016) and focuses on the possibility that the same outcome may follow from different combinations of conditions (Ragin, 2008).

Second, the analysis is conducted under the lens of science-based institutions, that is, research institutions different from those affiliated to a university. While partner choice and the relevance of university-industry R\&D alliances has been widely documented in the literature (Ankrah and Omar, 2015; de Wit-de Vries et al., 2019; Mascarenhas et al., 2018), existing research has overlooked the underlying reasons guiding other types of research institutions to embark on $R \& D$ alliances and their criteria for partner selection when conducting joint research with industrial partners. We believe this topic to be of great interest as the promoting of consortia between firms, universities, research centres and other public entities is central to the science and technology policy in Europe.

Third, we are able to confront different strategies that research institutions follow when deciding to enter in a R\&D partnership. Specifically, we obtain four combinations that vary in their particular composition, yet, they all turn into a successful partnership, thus providing vision for complementarity effects among factors that otherwise, would have remained unnoticed. These strategies have been labelled taking into account the ties 
between the partners and by interpreting how the interplay of the factors leads to the desired outcome. Understanding the rationale behind each of these strategies is important for technology policy, being particularly useful in the initial stages of an R\&D alliance when evaluating the attractiveness of the partner and deciding whether (or not) to embark on a collaborative agreement.

The remainder of the study is organised as follows. Section 2 reviews those factors that, according to the literature, are more likely to shape the performance of sciencebusiness R\&D alliances. Next, in section 3, we describe the data sample and the methodological approach. The empirical results are presented section 4 , followed by a discussion (section 5) of the implications. The paper ends with some concluding remarks and suggests new research avenues for future studies.

\section{Theoretical underpinnings}

Alliance success is largely conditioned by the smart selection of the partner (Shah and Swaminathan, 2008). Understanding under which circumstances certain partners are more attractive is a relevant issue for making more informed decisions aimed to guarantee the success of the alliance.

As a starting point for determining the most common factors influencing partner selection and, in turn, alliance success, we undertook a comprehensive review of the literature on $R \& D$ alliances. The revision uncovered different factors that were grouped into five main ones, namely: planning, profile of the partner, trustworthiness, negotiation of intellectual property rights (IPR) issues and communication. These factors cover those that have been consistently identified in prior studies (e.g. Jacob et al., 2013; MartínezNoya and Narula, 2018; Shah and Swaminathan, 2008), confirming that they are meaningful to the purpose of this research and are likely to shape the success of the alliance.

To the best of the authors' knowledge, the originality of the present study stems from examining the simultaneous effect of the above factors and how they can be combined. In the paragraphs that follow, we review each of these factors individually.

\subsection{Planning}

Planning has traditionally been considered an important determinant for achieving success. The main outcome of the initiation phase is a contract agreement, where a clear definition of what is expected to be obtained as a consequence of the partnership should be approved (Plewa et al., 2013). Several elements need to be agreed upon. Goals and priorities, milestones, deliverables, timelines and the allocation of roles and responsibilities shape the boundaries of the collaborative agreement. Also, equity in sharing costs and risks has been shown to stimulate favourable agreements (Veugelers and Cassiman, 2005).

Because of different ways of operating, differences among partners may arise. In addition, some knowledge might be subject to secrecy policies, and partners may insist on protecting their own technologies before sharing them with the partner. During the planning stage, it is necessary to come up with a contractual agreement where partners feel comfortable. If the contract is well-defined and structured, it will facilitate the establishment of mutually beneficial synergies and may prevent the development of false 
expectations concerning the alliance (Sherwood and Covin, 2008). For this to take place, the requirements and responsibilities of the partners must be identified as early as possible. However, experience reveals that many misunderstandings arise because the planning stage is often too rushed (Robson et al., 2012). Thus, it is important that technology centres dedicate time and effort to this stage, as a good plan sets the partnership up for success.

\subsection{Partner profile}

The profile of the industry partner plays an important role in predicting the success of the partnership (Perkmann et al., 2013). Research suggests that a positive prior experience with an industrial collaborator will probably increase the likelihood of the research centre renewing the collaborative agreement (Bekkers and Bodas Freitas, 2008; D'Este and Patel, 2007). If the initial experience was positive, repeating the alliance may increase partners' capacity to absorb the knowledge resulting from the joint activity. Likewise, it will develop more efficient and effective knowledge transfer processes and may grow into a long-term relationship (Zahra and George, 2002).

Another element that needs to be taken into account is the knowledge and expertise of each partner concerning the technology to be developed (Mora-Valentin et al., 2004). The partners' prior experience is expected to foster understanding between the shareholders, as both parties will be better able to comprehend the assumptions along with the extent and significance of the details that shape the technology of interest (Perkmann et al., 2013). Furthermore, due to common interests, the willingness to get involved in a knowledge transfer alliance will increase greatly (Lai, 2011). Likewise, as organisations learn through various processes, firms that have previously been involved in knowledge transfer alliances will also be more likely to understand collaborative possibilities, how to successfully engage in them and what should be avoided (Kale et al., 2002).

Lastly, it is worth considering the geographical proximity of the partners (Herrmann et al., 2012; Santoro and Gopalakrishnan, 2000). It has been argued that closeness is a driving factor for the establishment of science-business partnerships (Lindelöf and Löfsten, 2004; Munari et al., 2011). However, some studies have shown that not just proximity but an extensive social capital comprising meaningful interactions between scientists and market agents is what really matters (Aldridge and Audretsch, 2011).

\subsection{Trustworthiness}

Partner trust acts as a facilitator of access, know-how and exchange of information across the alliance interface (Kale et al., 2000). Sherwood and Covin (2008) observed that if the partner's knowledge of the state of the art is not up to date, any information shared might be regarded as potentially tainted. The development of a trusting relationship between the knowledge source and knowledge-seeking partner is therefore desired (Jiang et al., 2015; Sampson, 2005).

Prior research identifies trust as a critical feature, particularly when information about the partner is not fully available or is incomplete (Krishnan et al., 2006; Nielsen and Nielsen, 2009). Specifically, trust reduces the level of asymmetric information. Commitment in an R\&D alliance entails both the transferor and the transferee investing the maximum effort in terms of time and resources on behalf of the alliance, thus involving a willingness to sustain the alliance for the long term. This attitude facilitates 
decision-making and creates a flexible working environment, thereby reducing the complexity and potential disagreements among stakeholders (Berbegal-Mirabent and Llopis-Albert, 2016).

The higher the level of trust between partners, the greater their involvement in and commitment to the alliance (Mora-Valentin et al., 2004). Accordingly, building an atmosphere of trust is essential in order to contribute to the free exchange of information between committed partners. Moreover, this atmosphere allows both parties to understand the value of their respective offers better, and consequently partners are more highly motivated to proceed in order to achieve the goal.

Building on the trust literature, in this study we go a step further and consider trustworthiness as a key antecedent for alliance success. The concept of "trustworthiness" captures the degree to which a partner is perceived not to exploit one's exchange vulnerabilities (Mayer et al., 1995), covering the cognitive, intentional and emotional evaluations of whether the other party can and will fulfil expectations-e.g. keeping commitments, negotiating honestly, and avoiding taking excessive advantage of partner organisations-(Cummings and Bromiley, 1996). This approach is very similar to the one adopted by Butler (1991) who also highlighted the relevance of consistency and promise fulfilment when defining this term. A partner that is trustworthy is expected to behave ethically (i.e. integrity), show benevolence (i.e. a positive rather an egocentric orientation) and possess the right skills and competences that qualify him/her to effectively perform the tasks assigned (i.e. ability).

Trustworthiness may lead to lower transaction costs (Dyer and Chu, 2003), enhanced learning (Li et al., 2010; Szulanski et al., 2004) and can more easily yield to efficiency and flexibility and thus, sustainable competitive advantage (Chen et al., 2011). Not surprisingly, previous authors suggest a positive relationship between trustworthiness and performance outcomes (Dyer and Singh, 1998). Thus, similar to previous works in the field of strategic alliances (Becerra et al., 2008; Li et al., 2008; Schilke and Cook, 2015) we argue that for collaborative relationships to succeed, trustworthiness among the partners might play a key role.

\subsection{IPR protection}

The cost and risk associated with an R\&D contract may act as a barrier to cooperation and hinder knowledge transfer alliances (Veugelers and Cassiman, 2005). In order to minimise this obstacle, it is important to clearly state how IPR are going to be managed. Both firms and technology centres are internally regulated to protect and safeguard their technologies and expertise before sharing them with third parties. This holds true particularly in the case of technology centres affiliated with a university or a public research institute. Traditionally, such entities have developed internal policies as well as new infrastructures to foster industry-science collaborative research partnerships. Whereas the former may include the establishment of regulatory frameworks for the devolution of IPR, patents or licenses, the latter involves the creation of knowledge transfer offices, which act as intermediary structures. Indeed, many studies highlight the importance of these units as decisive agents in the success of the partnership (Friedman and Silberman, 2003).

The disclosure and commercialisation of the outcomes resulting from a joint partnership are expected to generate profits. Although previous research has shown that science-industry R\&D alliances tend to be already underway before signing the 
collaboration contract, IPR protection issues should be agreed upon in the early engagement phase of the alliance in order to avoid potential conflicts (Plewa et al., 2013).

While detailed contracts should be used to reduce risk, an excessive rigidity can obstruct the success of the alliance. In today's fast and competitive environment, speed and innovation are key factors. As a result, changes in the priorities and the nature of interactions between partners may occur over time (Bruneel et al., 2010). Thus, in order to remain on the cutting edge, although explicit policies and working protocols are needed, a flexible normative framework that allows the introduction of readjustments might also be useful.

\subsection{Communication channels}

Because each partner is somehow embedded in its specific context-having different needs, structures and mission-partners might only be able to understand each other's characteristics if a common goal is pursued (Barnes et al., 2002). Even when two partners have collaborated previously, communication is a challenging issue to manage due to the inherent human component that R\&D alliances entail. Trustworthiness and communication are two concepts very closely related to each other (Plewa et al., 2013). Trustworthiness fosters communication and knowledge exchange (Bruneel et al., 2010; Bruneel et al., 2015). In turn, communication is a prerequisite for trust and for assisting the partners' understanding of each other (Wittmann et al., 2009).

Variations in the perceived quality of the communications, potential breakdowns and miscommunications are some of the problems that partners may face (Sherwood and Covin, 2008). Additionally, it is widely acknowledged that scientists often do not speak the language of industry (Olazaran et al., 2009). Similarly, the exchange of sensitive information as well as the differing and often unfamiliar culture of the parties may generate high levels of uncertainty between them (Plewa, 2009). In such cases, information flow between the parties and the presence of multiple and complementary communication channels may help to minimise the aforementioned communication problems (Ybarra and Turk, 2009). Interaction strengthens the ties between partners, creating a knowledge platform interface that generates synergies and stimulates knowledge flows (Cummings and Kiesler, 2007).

Another relevant issue is that of complementarity of resources (Rothaermel, 2001). Harrison et al. (2001) further showed that resource complementarity, as opposed to similarity, is associated with improved performance. In the context of R\&D alliances we argue that in such situations - understanding resources either in terms of knowledge, technology or assets-communication issues gain importance, as it is of utmost importance to hold regularly meetings with the partner to stay updated and informed about any advancements and their potential impact on the alliance.

\section{Data and method}

\subsection{Sample and data collection}

Catalonia's R\&D system comprises universities, research centres, science parks, technology centres and private agents. This study focuses on technology centres integrated in TECNIO. Set up in 2009, TECNIO is the umbrella brand that brings 
together the Catalan technology centres and aims to reduce the gap between the knowledge created at technology centres and its commercialisation. These centres are defined as technological agents whose purpose is to improve the competitiveness of firms through the generation, development and diffusion of technology. They should be constituted as not-for-profit entities with headquarters in Catalonia. To qualify as a TECNIO centre, there are a series of requirements (e.g. percentage of income from R\&D activities with companies, composition of the workforce, not surpassing a specific percentage of funding coming from public sources, etc.) that should be satisfied. The Catalan government, through ACCIÓ (Agency for the Competitiveness of Firms) is in charge of evaluating prospective centres willing to be included in this network. At the time this study was conducted, TECNIO comprised 102 technology centres operating in a wide range of sectors.

A questionnaire (see section 3.2. for the details) was distributed by email to the 102 technology centres. The targeted respondents were managers with practical experience in the establishment of R\&D partnerships. Respondents mainly identified themselves as general managers (43.1\%) and heads of the technology transfer department (34.48\%). Seventy-one responses were received, which constituted an acceptable response rate of $69.6 \%$. Out of the 71 questionnaires returned, only 58 were fully completed. Among the 58 valid respondents, 44 questionnaires came from technology centres affiliated with a university or public research centre and the remaining 14 from independent not-for-profit entities.

\subsection{Measures}

As state above, a questionnaire was designed, consisting of two sections. The first section contained questions concerning the specific characteristics of the centre and the income generated, while the second was a list of 17 items to which respondents should express their degree of accordance based on a 5 -point Likert scale $(1=$ strong disagreement; $5=$ strong agreement). Following the work of Shah and Swaminathan (2008), the factors were operationalised using multiple item measures that were developed based on the ideas presented in the literature pertaining to alliances and through interviews, mainly with people from ACCIÓ (the agency in charge of evaluating the eligibility of technology centres). Wherever possible, existing measures of the constructs were adapted and used. Table 1 contains detailed descriptions of the items that refer to the five factors described in the literature review section.

\section{Insert Table 1 about here}

Planning. Drawing from a variety of sources (Bstieler et al., 2015; Fernandes et al., 2015; Morandi, 2013; Perkmann et al., 2011), a four-item scale for planning was developed. The scale captures the relevance of defining a joint objective setting. Thus, items refer to the importance given to aligning interests among partners, defining the objectives and outcomes, the roles to be performed by each of the partners, and the necessary mechanisms (e.g. meetings, reports) to be implemented to make sure all partners have a common goal.

Partner profile. For the purpose of this study, partner profile is defined in terms of how critical the following dimensions are with respect to partner attractiveness: complementarity of resources (i.e. working with others), establishing alliances with 
existing partners (i.e. based on positive experiences) and looking for long-term alliances (i.e. cost of opportunity of constantly changing partners and consequently, starting each time from scratch). Note that because TECNIO centres are mainly targeted at boosting the technological capability of Catalan firms, we decided not to include an additional item asking for the relevance of geographical proximity, as the majority of the business partners are closely located.

Trustworthiness. Consistent with the conceptualisation previously described, this construct is operationalised as a four-item factor which accounts for the willingness of the partners to establish win-win contractual arrangements (Franco, 2011) in which to allocate time and resources, looking for a long-term relationship and mutual benefit. The items of this construct also capture the importance of creating an enabling atmosphere where problems can be discussed, and the purpose of the partnership arranged accordingly.

$I P R$ protection. This factor is operationalised through three items which capture the point of view of science-based institutions with respect to the willingness and relevance placed in discussing and finding a common agreement concerning the management of outcomes resulting from the alliance (intellectual property rights). Previous literature on this matter highlights the importance of using formal protection mechanisms, particularly when market uncertainty is high ( $\mathrm{Li}$ et al., 2008) — as in our case, where R\&D alliances are established for the development of new technology.

Communication channels. Two items are included in this factor, based on an evaluation of the existing literature discussing communication issues in $R \& D$ alliances. In this sense, the items mirror the importance of establishing processes and structures that facilitate information flows as a strategy to mitigate potential barriers due to information asymmetry (Abramo et al., 2011), even in the event of sensitive information. Also, this factor accounts for the relevance granted to the complementarity of resources (Kim, 2012). We posit that in such contexts-where partners have diverse areas of specialisation-communication issues are even more necessary.

\subsection{Method}

A principal component factor analysis was used as an exploratory tool for grouping the items included in the survey into factors. Because items included in the survey were based on the literature, factor analysis was used as a technique to further validate the grouping of the items.

Next, in order to explore which combination of factors can lead to success in R\&D partnerships, in a second stage we used qualitative comparative analysis (QCA). Causal complexity is assumed by this method, allowing combined effects of antecedent conditions to reach an outcome. QCA also entails equifinality, meaning that there are multiple paths (different starting points) that yield a similar outcome. One additional feature that makes QCA attractive is that it works well with small samples, although it can also be applied to large samples (Fiss, 2011). Furthermore, this method has been proven to be useful in explaining performance in similar settings (Berbegal-Mirabent and Llopis-Albert, 2016).

QCA uses Boolean logic instead of the traditional correlation methods to set causal conditions strongly related to a particular outcome (Ragin, 2008). Its fundamentals rely on the analysis of sufficient and necessary conditions to produce an outcome. One condition is deemed necessary if it is present in all instances of the outcome. A condition 
will be sufficient if a particular outcome emerges whenever the condition is present (Schneider and Wagemann, 2012).

\section{Results}

We first computed Bartlett's test of sphericity, obtaining $\chi^{2}=385.592$ with 120 degrees of freedom. As the $\mathrm{p}$-value $=0.000$, we concluded that the data set was appropriate for the factor analysis. The Kaiser-Meyer-Olkin test value also corroborates the adequacy of factor analysis as a sampling methodology $(\mathrm{KMO}=0.657$ at a significance of 0.000 , exceeding the threshold value of 0.6). The statistical treatment of data was performed using the SPSS software package.

The principal component factor analysis was performed next. Retaining only those factors whose eigenvalues exceed a specified value ( $>1$ according to the Kaiser (1960) criterion), five factors should be taken, explaining $69.96 \%$ of the variance. We then moved on to analyse the items included in each factor by using an orthogonal rotation method (varimax). Results are shown in Table 2, including only the loadings of those items that best contribute to explain each of the factors (loadings $>0.5$ ).

\section{Insert Table 2 about here}

Results corroborate our grouping of items. Factor 1 includes those items related to the initial stages of an R\&D agreement (planning). Factor 2 refers to the profile of the partner, while factor 3 is concerned with the commitment that all active parts should assume. Factor 4 covers those items referring to IPR protection issues. Finally, factor 5 concentrates on the channels and internal mechanisms that facilitate communication between partners.

The unidimensionality and reliability of the multi-item factors was next assessed, conducting five independent exploratory factor analyses. In all instances, only one factor was extracted, supporting our view that the measurement instrument is sound. The results of the analysis are also reported in Table 2. Both the Cronbach's alpha and composite reliability (CR) surpass the cut-off point of 0.6 , indicating good internal consistency among the items within each factor (Malhotra, 2004).

The correlation results shown in Table 3 further corroborate that the square root of the average variance extracted (AVE) for each of the factors is greater than the correlations between each construct and all other latent variables (Fornell and Larcker, 1981), therefore proving the discriminant validity of the constructs.

\section{Insert Table 3 about here}

Next, a qualitative comparative analysis was performed. The five factors listed in Table 1 were used as antecedent conditions. The outcome was operationalised through the income resulting from $R \& D$ alliances of the technology centre in the year divided by the total number of clients. Following the QCA methodology, Table 4 shows how variables were transformed into sets. As both the outcome and the five factors are continuous values, a fuzzy-set transformation is required. This process, known as calibration, permits expressing sets according to the degree of membership in a given condition (Ragin, 2008). Membership scores range from 0 (full non-membership) to 1 
(full membership). Observations falling in $90^{\text {th }}$ percentile represent the threshold of 0.95 , indicating full membership. The $10^{\text {th }}$ percentile is used as the 0.05 cut-off point and denotes full non-membership. The crossover point $(0.5)$ is calculated using the median and denotes cases with the maximum ambiguity with respect to their membership in the set.

\section{Insert Table 4 about here}

QCA requires a test of whether the antecedent conditions are necessary to produce the desired outcome (Meyer et al., 1993). Consistency scores higher than 0.9 indicate necessity. As reported in Table 5, there is no antecedent condition that alone can predict the outcome; therefore, these preliminary results seem to support our argument that the outcome results from a conjunction of different factors.

\section{Insert Table 5 about here}

In the next step, the truth table was calculated. Given $\mathrm{k}$ condition sets, the truth table contains $2^{\mathrm{k}}$ rows. Each column represents a condition and each row the empirical cases. Cases are assigned to the combinations in which their membership scores are greater than 0.5. Lastly, using Boolean algebra, a logical reduction of statements is generated. In this process, rows are reduced based on two parameters: coverage (which indicates the empirical relevance of a solution) and consistency (which quantifies the extent to which cases sharing similar conditions have the same outcome). Both measures range from 0 to 1. According to Ragin (2008), a minimum consistency of 0.75 and coverage of 0.45 indicate goodness of fit.

Results are displayed in Table 6, revealing four different recipes that lead to the desired outcome. In order to systematise the comparison of the solutions, we use the distinction between core and peripheral conditions (Fiss, 2011). Core conditions represent the essential causes that have a strong causal relationship with the outcome of interest, while peripheral conditions are those that are more expendable as they are contingent on specific segments. The solution coverage is 0.471 and the consistency is 0.807 . Each of the four configurations also shows acceptable consistency scores, all above 0.842. Raw coverage is also significantly high, indicating that the extent to which each recipe explains the outcome is sound. Contrarily, unique coverage is rather low, meaning that the proportion of cases that can be explained exclusively by the configuration is low. Said differently, cases in the sample emerge from a combination of the different recipes.

\section{Insert Table 6 about here}

From the reading of Table 6 , it can be inferred that planning is not that critical. In fact, this factor only appears in two of the four configurations. Specifically planning is relevant (configuration \#1) when combined with partner profile and communication channels, although trustworthiness being limited. This first configuration indicates that when the technology centre looks for a partner with whom it is easy to collaborate (because of a positive previous experience or and there is fluid flow and exchange of information), devoting time and efforts in the planning stage is critical, particularly when there is no evidence about how the partner will behave throughout the partnership 
(absence of trustworthiness). Still in the assumption of having some interrogates about how trustworthy is the partner, in those cases where the partnership cannot be carefully planned (as in configuration \#4), IPR and communication channels are of utmost importance to ensure the success of the partnership although knowing little the other partner.

A different solution is that shown in configurations \#2 and \#3. In both cases, IPR issues play an essential role, particularly in configuration \#3 where it stands as a core condition (also in \#4). These configurations also share the common feature of having the communication strategy little developed. According to these findings it can be concluded that when communication channels are not working effectively, a science-industry R\&D partnership can still be worthwhile but only if IPR issues are clearly discussed and formalised. What makes these two recipes different is the familiarity with the partner (being familiar in configuration \#3, but having no previous relationship in \#2) and a shared vision about what trust and commitment actually mean (present in configuration $\# 2$, but absent in \#3). It is also worth noting that in configuration \#3 all conditions are core, thereby indicating the existence of fewer choices with greater constraints when aiming for high performance of the $R \& D$ alliance.

\section{Discussion and implication of the results}

Different types of R\&D partners offer different advantages (Martinez-Noya and Narula, 2018), meaning that the rationale behind an alliance might shape the decision of which partner to choose. Selecting the right partner and setting the right band-width or scope of the interaction is a challenging topic that, although offering promising research opportunities in the field of strategic management of alliances, to date has received little attention (Miotti and Sachwald, 2003).

This study aims at filling this gap. From the standpoint of technology centres we have identified four different strategies that although being all valid and successful, are underlined by different purposes of the alliance.

Specifically, there is a first strategy (configuration \#1) that can be labelled as pathdependent, that is, there is an overall positive perception of the partner as a result of a prior collaboration; yet, there is limited knowledge about this connection, consequently, although the partner has de right profile, there is a perception of moderate or week trust. In order to mitigate this weakness, the technology centre places strong emphasis in defining a solid planning of the alliance (settling the "rules" before starting working together) and in building a strong communication mechanism to ensure constant exchange of information. One plausible explanation behind this strategy can be found in the concerns about search costs, which can prevent the technology centre from looking beyond the own existing network. Because of that, it is preferable to rely on existing contacts, which might be perceived as reducing the causal ambiguity surrounding knowledge exchange and, therefore, contribute to create a more efficient working environment. The saying "better the devil you know than the devil you don't know" can be used to exemplify this partnership. Under this lens, it is preferred (and safer) to do business with someone already known (even though there are some aspects of the partner that are not of our liking), than working with a stranger.

The second strategy (as deployed in configuration \#2) suggest R\&D alliances built upon trustworthy and reliable connections, denoting that although the partners might not 
have previously worked together with the technology centre, they know each other well, and there is no perceived risk about the integrity, benevolence and ability of the other, even when there is the opportunity of taking advantage of each other. The presence of the factor IPR protection indicates that partnership following this scheme have a markedly market orientation. Accordingly, IPR issues need to be discussed and formalised - aiming at protecting the market value that will be created - which, in turn, further strengthens a climate of trust and commitment. Results are thus exploited together, so it is important to contractually establish the shares in the ownership (for instance, it could be done through a joint venture). Another key feature characterising this configuration is that the prospective partner is perceived to "speak the same language"; consequently it is unnecessary to devote time and effort in defining sophisticated communication channels as there is low level of information asymmetry. Taking into account the previous considerations we suggest naming this alliance as partnering with colleagues.

An alternative strategy is that shown in configuration \#3. Similar to the pathdependent strategy, here the industry partner is perceived to qualify for the partnership (e.g. has the technology, expertise, know-how or adequate resources); however, there are some concerns about its commitment and ability/willingness to behave opportunistically. Similar to Li et al. (2008), alliances following this strategy can be labelled as partnering with an acquaintance. In this case, the partner is someone already known or a firm with whom the technology centre has already worked with but, due to few prior connections, there are some doubts about whether it is fully trustworthy or not. Also fluid communication channels are absent. Due to this scepticism and because of potential asymmetries of information, the technology centre will place strong emphasis in formalising an agreement covering issues like ownership of IP, as IP arrangements make opportunistic behaviours more difficult. An example that can be used to illustrate this strategy is that of an industry partner that only contributes with some specific but key resources (e.g. technology, equipment, funding) and is the technology centre who mainly develops the project. In such scenario, communication flows are perhaps not that relevant, but what is imperative is how the final result will be disclosed and what each partner will get from it. Therefore, a proper agreement on IPR is critical.

Last, but not least, the fourth strategy (configuration \#4) refers to partnering with outsiders, that is, partners that are not yet part of the network of the technology centre and thus, there is no previous experience in working with them. Not surprisingly, the factors partner profile and trustworthiness are absent in this configuration. To make this alliance successful the definition of a legal framework for the exploitation of the joint results is critical. The rationale for this partnership might be the need for a specific resource (i.e. skill, technology, knowledge) for developing the project and thus, either the technology centre or the industrial partner approaches the market in search of it. In such alliances, managing the tension between knowledge sharing and knowledge leakages is an everyday concern. This argument particularly holds true in projects aimed at creating radical innovation, where uncertainty and risk are higher, arising concerns about the safety of the technological assets. Thus, to overcome (un)intended opportunistic behaviours - aimed at appropriating a partner firm's core technologies — defining formal protection mechanisms is essential. However, as suggested by Li et al. (2008) in some situations formal protection may not be effective enough and even hinder flexibility and creativity. One way to overcome this problem is to establish a fluid communication strategy, which will also help reduce the absence of planning. This lack of planning can 
be explained by having the two partners working in different areas of the project, which might imply that the alliance is not intense in interactions between the partners (also consistent with the idea of lack of trustworthiness), on the contrary, the project can be split into two independent parts, yet, being both of them critical for completing the project as a whole.

Four main conclusions can be drawn from the analysis of the configurations described above. First, the negotiation of IPR issues at the initial stage is paramount (this condition appears in three out of the four configurations, and in two of them as a core condition). This finding is in accordance with the work of Kim (2012), who proposes that to innovate successfully, the management of intellectual properties is a key factor on the same level as factors such as corporate management, the quality and composition of the management team or the efficiency of business operations and operational structure. Second, commitment and communication channels seem to act interchangeably. That is, in the absence of trustworthiness, information flows through communication channels are essential, and a strong commitment of the partners counterbalances a poor communication strategy. Third, when there is no previous experience with the partner, trustworthiness (configuration \#2) or, in its absence, communication channels (configuration \#4) are the key to success. Fourth, planning is not as relevant as expected. The rationale for this might be found in the fact that the majority of the R\&D alliances under analysis deal with the development of new technology. Because of the dynamic and volatile environment, the likelihood of pivoting during the lifecycle of the R\&D alliance is high; therefore, the strategy needs to be constantly refined. This finding is consistent with Narula (2001) who argues that R\&D agreements should be flexible enough to enable amendments without causing much impact on the outcomes of the alliance.

In light of these findings, several managerial implications are in order. Internal regulatory frameworks set the 'rules of the game'. In this respect, industries and sciencebased institutions should design and implement flexible normative schemes that facilitate an agreement on how the outcomes resulting from an R\&D alliance should be exploited. Research institutions and companies have different cultures, which might manifest in divergent objectives, time orientations, languages and expectations (Martínez-Noya and Narula, 2018). These features are likely to sow misunderstanding, complicating the ultimate purpose of the alliance. Control over IPR or conflicts of interest are common threats that can impinge on a sound negotiation. Expectations and procedures concerning how negotiations will be conducted need to be clarified before signing any agreement. Instead of adopting an aggressive strategy towards negotiations over IPR, partners must feel that negotiations will result in mutually beneficial joint decisions and that they involve not only representatives of both parties but also the knowledge holders (including key research personnel from both sides). Public administrations also have a key role in promoting cooperative activities between institutions in charge of generating new knowledge and industries $(\mathrm{Li}, 2010)$. If public policies are not intentionally $\mathrm{R} \& \mathrm{D}$ oriented, the science-industry ecosystem may suffer from a lack of support, which in turn will hamper innovation development and will consequently hinder the economic growth of regions. 


\section{Concluding remarks}

Partnerships between science-based institutions and industries are proliferating. Among those forms of collaboration that have spurred increased attention in recent years are $R \& D$ contracts, where a research institution carries out an $R \& D$ project as a response to a specific firm's request. This research activity leads to new knowledge, subject to uncertainty.

R\&D alliances are established on a win-win basis (Franco, 2011). Research institutions are provided with additional funding sources - compensating for the decrease in public support due to the global economic downturn - which can help improve the state of the art, generate new ideas and improve researchers' performance. Conversely, companies are able to tap into cutting-edge knowledge, expertise and resources. However, some of these alliances do not work and are terminated with little or no benefit to either of the partners.

Given that R\&D contracts represent one of the biggest revenue-generating knowledge-transfer outputs (Martínez-Noya and Narula, 2018), the study of how these partnerships materialise becomes a matter of interest for both academics and policymakers. By adopting the viewpoint of science-based institutions, in this study we have provided new insights into those factors (and their combinations) that shape R\&D alliances. For the purpose of this study, we have focused our attention on five factors, which, according to the literature, are expected to play a critical role. These factors are related to the choice, relationship and communication channels with the partner, the planning of the alliance and the negotiation of IPR rights.

The original contribution of this work stems from acknowledging that partner selection is a complex strategic decision in which multiple factors are confronted together and the final decision does not always rely on the same factors but is highly dependent on the purpose of the alliance and the specific needs of the partner. This work theoretically contributes to the existing literature on alliance management by putting forward that $\mathrm{R} \& \mathrm{D}$ alliances are heterogeneous and therefore should be examined under alternative approaches that allow for capturing this causal complexity. Thus, instead of analysing the net effects of the factors, we rely on qualitative comparative analysis. By using this method factors are considered not only in an individual fashion but in a more realistic and complex setting in which they coexist and overlap. The empirical analysis proves the existence of different strategies (i.e. different ways of combining the factors), all of them leading equally to fruitful $R \& D$ alliances.

Another distinguishing feature of this work is that, contrary to the majority of the studies on R\&D alliances between science-based institutions and firms, we do not take the university as the unit of analysis but instead focus on a different type of research institution (in this case, technology centres), which has been largely ignored despite playing a critical role in the innovation ecosystem.

Future studies should consider expanding the sample and include other types of science-based institutions. In addition, comparative studies on how different types of research centres conceive $R \& D$ alliances might report interesting findings that would undoubtedly provide thought-provoking insights to be considered by policymakers. 


\section{References}

Abramo, G., D’Angelo, C.A., Di Costa, F. and Solazzi, M. (2011) 'The role of information asymmetry in the market for university-industry research collaboration', Journal of Technology Transfer, Vol. 36, No. 1, pp. 84-100.

Aldridge, T.T. and Audretsch, D. (2011) 'The Bayh-Dole Act and scientist entrepreneurship', Research Policy, Vol. 40, No. 8, pp. 1058-1067.

Ankrah, S. and Omar, A.T. (2015) 'Universities-industry collaboration: A systematic review', Scandinavian Journal of Management, Vol. 31, No. 3, pp. 387-408.

Barnes, T., Pashby, I. and Gibbons, A. (2002) 'Effective university-industry interaction: A multi-case evaluation of collaborative R\&D projects', European Management Journal, Vol. 20, No. 3, pp. 272-285.

Becerra, M., Lunnan, R. and Huemer, L. (2008) 'Trustworthiness, risk, and the transfer of tacit and explicit knowledge between alliance partners', Journal of Management Studies, Vol. 45, No. 4, pp. 691-713.

Bekkers, R. and Bodas Freitas, I.M. (2008) 'Analysing knowledge transfer channels between universities and industry: To what degree do sectors also matter?', Research Policy, Vol. 37, No. 10, pp. 1837-1853.

Belderbos, R., Carree, M. and Lokshin, B. (2004). 'Cooperative R\&D and firm performance', Research Policy, Vol. 33, No. 10, pp. 1477-1492.

Berbegal-Mirabent, J. and Llopis-Albert, C. (2016) 'Applications of fuzzy logic for determining the driving forces in collaborative research contracts', Journal of Business Research, Vol. 69, No. 4, pp. 1446-1451.

Bruneel, J., D'Este, P. and Salter, A. (2015) 'The impact of financial slack on explorative and exploitative knowledge sourcing from universities: evidence from the UK', Industrial and Corporate Change, Vol. 25, No. 4, pp. 689-706.

Bruneel J., D'Este, P. and Salter. A. (2010) 'Investigating the factors that diminish the barriers to university-industry collaboration', Research Policy, Vol. 39, No. 7, pp. 858-868.

Bstieler, L., Hemmert, M. and Barczak, G. (2015) 'Trust formation in university-industry collaborations in the US biotechnology industry: IP policies, shared governance, and champions', Journal of Product Innovation Management, Vol. 32, No. 1, pp. 111-121.

Butler Jr, J.K. (1991) 'Toward understanding and measuring conditions of trust: Evolution of a conditions of trust inventory', Journal of Management, Vol. 17, No. 3, pp. 643-663.

Chen, J.V., Yen, D.C., Rajkumar, T.M. and Tomochko, N.A. (2011) 'The antecedent factors on trust and commitment in supply chain relationships', Computer Standards \& Interfaces, Vol. 33, No. 3, pp. 262-270.

Cummings, L.L. and Bromiley, P. (1996) 'The organizational trust inventory (OTI): Development and validation'. In R.M. Kramer and T.R. Tyler (Eds), Trust in Organizations: Frontiers of Theory and Research (pp. 302-330). Thousand Oaks, CA: Sage.

Cummings, J.N., and Kiesler, S. (2007) 'Coordination costs and project outcomes in multi-university collaborations’, Research Policy, Vol. 36, No. 10, pp. 1620-1634.

Cunningham, J.A. and Link, A.N. (2015) 'Fostering university-industry R\&D collaborations in European Union countries', International Entrepreneurship and Management Journal, Vol. 11, No. 4, pp. 849-860. 
D'Este, P. and Patel, P. (2007) 'University-industry linkages in the UK: What are the factors underlying the variety of interactions with industry?', Research Policy, Vol. 36, No. 9, pp. 1295-1313.

de Wit-de Vries, E., Dolfsma, W.A., van der Windt, H.J. and Gerkema, M.P. (2019) 'Knowledge transfer in university-industry research partnerships: A review', Journal of Technology Transfer, Vol. 44, No. 4, pp. 1236-1255.

Dyer, J.H. and Chu, W. (2003) 'The role of trustworthiness in reducing transaction costs and improving performance: Empirical evidence from the United States, Japan, and Korea', Organization science, Vol. 14, No. 1, pp. 57-68.

Dyer, J.H., Powell, B.C., Sakakibara, M. and Wang, A.J. (2007) 'The determinants of success in R\&D alliances', Academy of Management Proceedings, Vol. 2007, no. 1, pp. 1-6. Briarcliff Manor, NY: Academy of Management.

Dyer, J.H. and Singh, H. (1998) 'The relational view: Cooperative strategy and sources of interorganizational competitive advantage', Academy of Management Review, Vol. 23, No. 4, pp. 660-679.

Fernandes, G., Pinto, E.B., Machado, R.J., Araújo, M. and Pontes, A. (2015) ‘A program and project management approach for collaborative university-industry R\&D funded contracts', Procedia Computer Science, Vol. 64, pp. 1065-1074.

Fiss, P.C. (2011) 'Building better causal theories: A fuzzy set approach to typologies in organization research', Academy of Management Journal, Vol. 54, no. 2, pp. 393420.

Fornell, C. and Larcker, D.F. (1981) 'Evaluating structural equation models with unobservable variables and measurement error', Journal of Marketing Research, Vol. 18, No. 1, pp. 39-50.

Franco, M. (2011) 'Determining factors in the success of strategic alliances: An empirical study performed in Portuguese firms', European Journal of International Management, Vol. 5, No. 6, pp. 608-632.

Friedman, J. and Silberman, J. (2003) 'University technology transfer: Do incentives, management, and location matter?', Journal of Technology Transfer, Vol. 28, No. 1, pp. 17-30.

Geigenmüller, A. and Leischnig, A. (2017) 'A configurational perspective on alliance management capabilities'. In T.K. Das (Ed), Managing alliance portfolios and networks. Research in strategic alliances (pp. 71-90). Charlotte, NC: Information Age Publishing.

George, A.L and Bennett, A. (2005). Case studies and theory development in the social sciences, MIT Press, Cambridge.

Harrison, J.S., Hitt, M.A., Hoskisson, R.E. and Ireland, R.D. (2001) 'Resource complementarity in business combinations: Extending the logic to organizational alliances', Journal of Management, Vol. 27, No. 6, pp. 679-690.

Herrmann, Am. M, Taks, J.L. and Moors, E. (2012). 'Beyond regional clusters: On the importance of geographical proximity for $R \& D$ collaborations in a global economy - The case of the Flemish biotech sector', Industry and Innovation, Vol. 19, No. 6, pp. 499-516.

Huang, J-J. (2009) 'Knowledge creation in strategic alliances based on an evolutionary perspective: A mathematical representation. Knowledge Management Research \& Practice, 7, 1, 52-64. 
Jacob, J., Belderbos, R. and Gilsing, V. (2013) 'Technology alliances in emerging economies: persistence and interrelation in European firms' alliance formation', $R \& D$ Management, Vol. 43, pp. 447-460.

Jiang, X., Jiang, F., Cai, X. and Liu, H. (2015) 'How does trust affect alliance performance? The mediating role of resource sharing', Industrial Marketing Management, Vol. 45, No. 1, pp. 128-138.

Kaiser, H.F. (1960) 'The application of electronic computers to factor analysis', Educational and Psychological Measurement, Vol. 20, No.1, pp. 141-151.

Kale, P., Dyer, J. H. and Singh, H. (2002) 'Alliance capability, stock market response, and long-term alliance success: The role of the alliance function', Strategic Management Journal, Vol. 23, No. 8, pp. 747-767.

Kale, P., Singh, H. and Perlmutter, H. (2000) 'Learning and protection of proprietary assets in strategic alliances: Building relational capital', Strategic Management Journal, Vol. 21, No. 3, pp. 217-237.

Kesting, T., Gerstlberger, W. and Baaken, T. (2018) 'A benefit segmentation approach for innovation-oriented university-business collaboration', International Journal of Technology Management, Vol. 76, No. 1-2, pp. 58-80.

Khamseh, H.M. and Jolly, D. (2014) 'Knowledge transfer in alliances: The moderating role of the alliance type', Knowledge Management Research \& Practice, Vol. 12, No. 4, pp. 409-420.

Kim, K.Y. (2012) 'Strategic R\&D alliance factors that impact innovation success in the biotechnology industry', International Journal of Technology Management, Vol. 59, No. $1 / 2$, pp. 116-138.

Krishnan, R., Martin, X. and Noorderhaven, N.G. (2006) 'When does trust matter to alliance performance?', Academy of Management Journal, Vol. 49, No. 5, pp. 894917.

Lai, W-H. (2011) 'Willingness-to-engage in technology transfer in industry-university collaborations', Journal of Business Research, Vol. 64, No. 11, pp. 1218-1223.

Lambert, D.M., Emmelhainz, M.A. and Gardner, J.T. (1996). 'So you think you want a partner?', Marketing Management, Vol. 5, No. 2, pp. 24-41.

Leischnig, A. and Geigenmüller, A. (2020) 'Examining alliance management capabilities in university-industry collaboration', Journal of Technology Transfer, Vol. 45, No. 1, pp. 9-30.

Li, J. (2010) 'Global R\&D alliances in China: Collaborations with universities and research institutes', IEEE Transactions on Engineering Management, Vol. 57, No. 1, pp. 78-87.

Li, D., Eden, L., Hitt, M.A. and Ireland, R.D. (2008) 'Friends, acquaintances, or strangers? Partner selection in R\&D alliances', Academy of Management Journal, Vol. 51, No. 2, pp. 315-334.

Lin, F.J., Wu, S.H., Hsu, M.S. and Perng, C. (2016). 'The determinants of governmentsponsored R\&D alliances', Journal of Business Research, Vol. 69, No. 11, pp. 5192-5195.

Lindelöf, P, and Löfsten, H. (2004) 'Proximity as a resource base for competitive advantage: University-industry links for technology transfer', Journal of Technology Transfer, Vol. 29, No. 3, pp. 311-326.

Link, A.N., Rothaermel, F.T. and Siegel, D.S. (2008) 'University technology transfer: An introduction to the special issue, IEEE Transactions on Engineering Management, Vol. 55, No. 1, pp. 5-8. 
Ma, R.K., Liu, F.C, and Sun, Y.T. (2018). Collaboration partner portfolio along the growth of Chinese firms' innovation capability: configuration, evolution and pattern', International Journal of Technology Management, Vol. 76, No. 3-4, pp. 163-187.

Malhotra, N.K. (2004). Marketing research and applied orientation (4th ed.). Prentice Hall: Upper Saddle River, NJ.

Martínez-Noya, A. and Narula, R. (2018). 'What more can we learn from R\&D alliances? A review and research agenda', Business Research Quarterly, Vol. 21, No. 3, pp. $195-212$.

Mascarenhas, C., Ferreira, J.J. and Marques, C. (2018) 'University-industry cooperation: A systematic literature review and research agenda', Science and Public Policy, Vol. 45, No. 5, pp. 708-718.

Mayer, R.C., Davis, J.H. and Schoorman, F.D. (1995) 'An integrative model of organizational trust', Academy of Management Review, Vol. 20, No. 3, pp. 709-734.

Meyer, A.D., Tsui, A.S. and Hinings, C.R. (1993) 'Configurational approaches to organizational analysis', Academy of Management Journal, Vol. 36, No. 6, pp. 1175-1195.

Miotti, L. and Sachwald, F. (2003) 'Co-operative R\&D: why and with whom? An integrated framework of analysis', Research Policy, vol. 32, No. 8, pp. 1481-1499.

Mora-Valentin, E.M., Montoro-Sanchez, A. and Guerras-Martin, L.A. (2004) 'Determining factors in the success of R\&D cooperative agreements between firms and research organizations', Research Policy, Vol. 33, No. 1, pp. 17-40.

Morandi, V. (2013) 'The management of industry-university joint research projects: how do partners coordinate and control R\&D activities?', Journal of Technology Transfer, Vol. 38, No. 2, pp. 69-92.

Munari, F., Sobrero, M. and Malipiero, A. (2011) 'Absorptive capacity and localized spillovers: Focal firms as technological gatekeepers in industrial districts', Industrial and Corporate Change, Vol. 21, No. 2, pp. 429-462.

Muscio, A., Quaglione, D. and Vallanti, G. (2014) University regulation and universityindustry interaction: a performance analysis of Italian academic departments', Industrial and Corporate Change, Vol. 24, No. 5, pp. 1047-1079.

Narula, R. (2001) 'Choosing between internal and non-internal R\&D activities: Some technological and economic factors', Technology Analysis \& Strategic Management, Vol. 13, No. 3, pp. 365-387.

Nielsen, B.B. and Nielsen, S. (2009) 'Learning and innovation in international strategic alliances: An empirical test of the role of trust and tacitness', Journal of Management Studies, Vol. 46, No. 6, pp. 1031-1056.

Olazaran, M., Albizu, E. and Otero, B. (2009) 'Technology transfer between technology centres and SMEs: Evidence from the Basque country', European Planning Studies, Vol. 17, No. 3, pp. 345-363.

Perkmann, M., Neely, A. and Walsh, K. (2011). How should firms evaluate success in university-industry alliances? A performance measurement system', $R \& D$ Management, Vol. 41, No. 2, pp. 202-216.

Perkmann, M., Tartari, V., McKelvey, M., Autio, E., Broström, A., D’Este. P., Fini, R., Geuna, A., Grimaldi, R., Hughes, A., Krabel, S., Kitson, M., Llerena, P., Lissoni, F., Salter, A. and Sobrero, M. (2013) 'Academic engagement and commercialisation: A 
review of the literature on university-industry relations', Research Policy, Vol. 42, No. 2, pp. 423-442.

Plewa, C. (2009) 'Exploring organizational culture difference in relationship dyads', Australasian Marketing Journal, Vol. 17, No. 1, pp. 46-57.

Plewa, C., Korff, N., Baaken, T. and Macpherson, G. (2013) 'University-industry linkage evolution: An empirical investigation of relational success factors', $R \& D$ Management, Vol. 43, No. 4, pp. 365-380.

Ragin, C.C. (2008) Redesigning social inquiry: Fuzzy sets and beyond. Chicago: University of Chicago Press.

Robson, M.J., Schlegelmilch, B.B. and Bojkowszky, B. (2012) 'Resource deployment stability and performance in international research-and-development alliances: A self-determination theory explanation', Journal of International Marketing, Vol. 20, No. 1, pp. 1-18.

Rothaermel, F.T. (2001) 'Complementary assets, strategic alliances, and the incumbent's advantage: An empirical study of industry and firm effects in the biopharmaceutical industry', Research Policy, Vol. 30, No. 8, 1235-1251.

Sampson, R.C. (2005) 'Experience effects and collaborative returns in R\&D alliances', Strategic Management Journal, Vol. 26, No. 11, pp. 1009-1031.

Santoro, M.D. and Gopalakrishnan, S. (2000) 'The institutionalization of knowledge transfer activities within industry-university collaborative ventures', Journal of Engineering and Technology Management, Vol. 17, No. 3-4, pp. 299-319.

Schilke, O. and Cook, K.S. (2015). Sources of alliance partner trustworthiness: Integrating calculative and relational perspectives. Strategic Management Journal, Vol. 36, No. 2, pp. 276-297.

Schneider, C.Q. and Wagemann, C. (2012) Set-theoretic methods for the social sciences: A guide to qualitative comparative analysis. Cambridge: Cambridge University Press.

Shah, R. and Swaminathan, V. (2008). 'Factors influencing partner selection in strategic alliances: the moderating role of alliance context', Strategic Management Journal, Vol. 29, No. 5, pp. 471-494.

Sherwood, A.L. and Covin, J.G. (2008) 'Knowledge acquisition in university-industry alliances: An empirical investigation from a learning theory perspective', Journal of Product Innovation Management, Vol. 25, No. 2, pp. 162-179.

Spithoven, A. and Teirlinck, P. (2015) 'Internal capabilities, network resources and appropriation mechanisms as determinants of R\&D outsourcing', Research Policy, Vol. 44, No. 3, pp. 711-725.

Stejskal, J. and Hajek, P. (2019). 'Modelling collaboration and innovation in creative industries using fuzzy set qualitative comparative analysis', Journal of Technology Transfer, Vol. 44, No. 3, pp. 981-1006.

Tidd, J. and Trewhella, M. (1997). 'Organizational and technological antecedents for knowledge creation and learning', R\&D Management, Vol. 27, pp. 359-375.

Tidström, A. (2009). 'Causes of conflict in intercompetitor cooperation', Journal of Business \& Industrial Marketing Marketing, Vol. 24, No. 7, pp. 506-18.

Valkokari, K., Paasi, J. and Rantala, T. (2012) 'Managing knowledge within networked innovation', Knowledge Management Research \& Practice, Vol. 10, No. 1, pp. 2740 . 
Veugelers, R. and Cassiman, B. (2005) 'R\&D cooperation between firms and universities: Some empirical evidence from Belgian manufacturing', International Journal of Industrial Organization, Vol. 23, No. 5, pp. 355-379.

Wittmann, C.M., Hunt, S.D. and Arnett, D.B. (2009) 'Explaining alliance success: Competences, resources, relational factors, and resource-advantage theory', Industrial Marketing Management, Vol. 38, No. 7, pp. 743-756.

Wright, M., Birley, S. and Mosey, S. (2004) 'Entrepreneurship and university technology transfer', Journal of Technology Transfer, Vol. 29, No. 3-4, pp. 235-246.

Ybarra, C. E. and Turk, T.A. (2009) 'The evolution of trust in information technology alliances', Journal of High Technology Management Research, Vol. 20, No. 1, pp. 62-74.

Zahra, S.A. and George, G. (2002) 'Absorptive capacity: A review, reconceptualization, and extension', Academy of Management Review, Vol. 27, No. 2, pp. 185-203. 


\section{List of Tables}

Table 1. List of items

\begin{tabular}{|l|l|l|}
\hline Factor & Item & Description \\
\hline \multirow{4}{*}{ Planning } & PL1 & $\begin{array}{l}\text { The objectives of the project must be defined with clarity and } \\
\text { precision. }\end{array}$ \\
\cline { 2 - 3 } & PL2 & $\begin{array}{l}\text { A clear assignment of the roles and responsibilities of each of } \\
\text { the partners must be made. }\end{array}$ \\
\cline { 2 - 4 } & PL3 & $\begin{array}{l}\text { It is advisable to implement a formalised and written work } \\
\text { dynamic. }\end{array}$ \\
\cline { 2 - 4 } Partner profile & PL4 & $\begin{array}{l}\text { Before starting the project, it is advisable to carry out several } \\
\text { meetings related to the technical aspects. }\end{array}$ \\
\cline { 2 - 4 } & PP2 & $\begin{array}{l}\text { Projects are better developed when the collaborators and our } \\
\text { centre have had previous agreements. }\end{array}$ \\
\cline { 2 - 4 } established.
\end{tabular}


Table 2. Loads of the five EFAs and statistics for their reliability analyses.

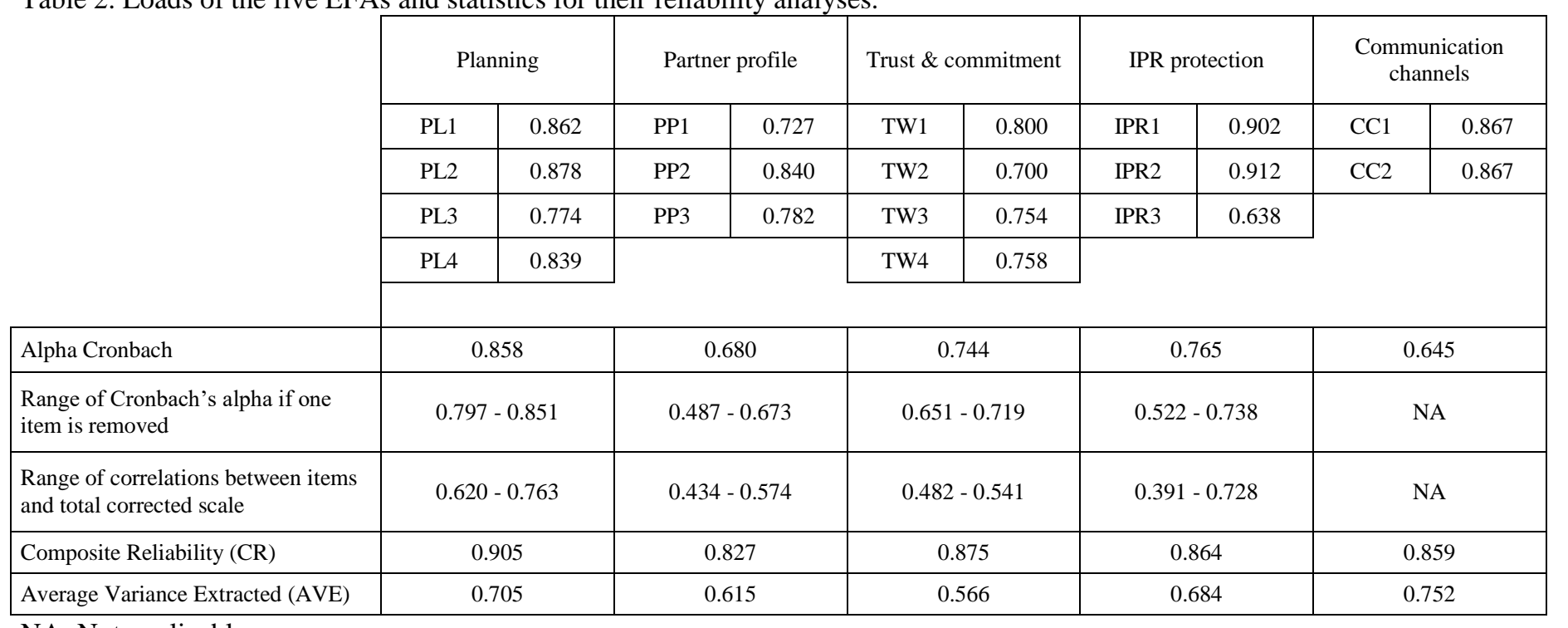

NA: Not applicable 
Table 3. Correlation matrix of latent factors

\begin{tabular}{|l|c|c|c|c|c|}
\hline Factor & 1 & 2 & 3 & 4 & 5 \\
\hline 1. Planning & 0.839 & & & & \\
\hline 2. Partner profile & 0.291 & 0.784 & & & \\
\hline 3. Trust and commitment & 0.314 & 0.458 & 0.753 & & \\
\hline 4. IPR protection & 0.012 & 0.275 & 0.265 & 0.827 & \\
\hline 5. Communication channels & 0.233 & 0.404 & 0.320 & 0.147 & 0.867 \\
\hline
\end{tabular}

All correlations are significant at the 0.01 level (bilateral).

Diagonal elements (in italics) are the square roots of the average extracted.

Table 4. Calibration of the outcome and the antecedent conditions

\begin{tabular}{|l|c|c|c|}
\hline \multirow{2}{*}{ Condition } & \multicolumn{3}{|c|}{ Membership threshold values } \\
\cline { 2 - 4 } & Full non-membership & Crossover point & Full membership \\
\hline Outcome: Income per client & 142192.70 & 26626.95 & 7934.53 \\
\hline Planning & 0.867 & 0.069 & -0.817 \\
\hline Partner profile & 1.553 & -0.145 & -1.377 \\
\hline Trust and commitment & 1.551 & -0.211 & -1.025 \\
\hline IPR protection & 1.069 & -0.081 & -1.054 \\
\hline Communication channels & 1.391 & 0.053 & -1.126 \\
\hline
\end{tabular}

Table 5. Analysis of necessary conditions

\begin{tabular}{|l|c|c|}
\hline Antecedent conditions & Consistency & Coverage \\
\hline Planning & 0.587 & 0.522 \\
\hline$\sim$ Planning & 0.624 & 0.618 \\
\hline Partner's profile & 0.632 & 0.553 \\
\hline$\sim$ Partner's profile & 0.686 & 0.692 \\
\hline Trust and commitment & 0.599 & 0.563 \\
\hline$\sim$ Trust and commitment & 0.621 & 0.580 \\
\hline IPR protection & 0.631 & 0.567 \\
\hline$\sim$ IPR protection & 0.561 & 0.543 \\
\hline Communication channels & 0.607 & 0.565 \\
\hline$\sim$ Communication channels & 0.727 & 0.685 \\
\hline
\end{tabular}

* The symbol ( ) represents the negation of the characteristic. 
Table 6. Sufficient configurations of antecedent conditions for performance

\begin{tabular}{|c|c|c|c|c|}
\hline \multirow{2}{*}{ Antecedent conditions } & \multicolumn{4}{|c|}{ Configurations } \\
\hline & 1 & 2 & 3 & 4 \\
\hline Planning & $\bullet$ & & & $\bigotimes$ \\
\hline Partners profile & $\bullet$ & $\otimes$ & $\bullet$ & $\otimes$ \\
\hline Trustworthiness & $\otimes$ & O & $\otimes$ & $\otimes$ \\
\hline IPR protection & & $\bullet$ & O & O \\
\hline Communication channels & $\bullet$ & $\otimes$ & $\otimes$ & $\bullet$ \\
\hline Raw coverage & 0.280 & 0.274 & 0.260 & 0.221 \\
\hline Unique coverage & 0.061 & 0.049 & 0.052 & 0.016 \\
\hline Consistency & 0.853 & 0.936 & 0.842 & 0.905 \\
\hline Solution coverage & \multicolumn{4}{|c|}{0.470} \\
\hline Solution consistency & \multicolumn{4}{|c|}{0.807} \\
\hline Frequency threshold & \multicolumn{4}{|c|}{1.000} \\
\hline Consistency threshold & \multicolumn{4}{|c|}{0.814} \\
\hline
\end{tabular}

Black circles $(\bullet)$ indicate the presence of a condition, and circles with $(\otimes)$ indicate its absence. Large circles indicate core conditions; small ones, peripheral conditions. Blank spaces indicate "don't care". 